\title{
The Unintentional Perpetuation of the Gender Divide
}

\author{
Aparna R. Parikh ${ }^{\top} \odot$, David A. Asch ${ }^{2}$, and Katrina Armstrong ${ }^{7}$ \\ 'Massachusetts General Hospital Cancer Center and Department of Medicine, Harvard Medical School, Boston, MA, USA; ${ }^{2}$ University of \\ Pennsylvania and Cpl Michael J Crescenz VA Medical Center, Philadelphia, PA, USA.
}

J Gen Intern Med 35(3):910-2

DOI: $10.1007 / \mathrm{s} 11606-019-05360-5$

(c) Society of General Internal Medicine 2019

$\mathrm{W}$ omen in academic medicine earn less than men; they advance less; and they lead less-disparities unexplained by rank, experience, effort, merit, or specialty. ${ }^{1-4}$ Conventional efforts to rectify these gaps concentrate on overcoming implicit and explicit biases faced by women. Like every other field, medicine is burdened by a range of workplace challenges including disrespect, inequity, and genderbased harassment. However, even workplace approaches to child-rearing - an area where academic medicine has devoted years of thought and effort - often fall short of their goals because of unintended consequences that perpetuate these gaps, or at least predictably fail to address them. ${ }^{5}$ We highlight three such examples to encourage fresh efforts toward gender equity - not to suggest these approaches will definitely succeed, but to recognize that even thoughtful and well-meaning efforts remain incomplete.

\section{PARENTAL LEAVE}

Dr. Okejumbe is a successful cardio-oncologist with a base salary of \$200,000. Her compensation plan includes 8 weeks of parental leave and annual salary increases of 0 to $5 \%$ based upon prior productivity. Giver her high productivity, her salary increased 5\% a year except for the years immediately following the births of her three children. Twenty years later, her base salary is $\$ 72,000$ lower than an equally productive colleague who joined at the same time but never took parental leave.

Pregnancy and parental leave can reduce long term compensation even in the face of seemingly supportive policies. When subsequent compensation is tied to past productivity, gaps in salary inevitably widen when compounded over a career. While productivity dips can be partly attributed to time away from practice, other factors also contribute. Clinicians planning for leave may receive fewer new referrals or accept

Received July 19, 2019

Accepted September 12, 2019

Published online October 21, 2019 fewer patients. Upon returning, clinicians predictably need increased flexibility for infant care. For scientists, parental leave may result in missing grant deadlines and disrupt the ability to complete experiments needed to produce pilot data for grants.

Seemingly discrete events, like childbirth, predictably propagate through the waves of a career, sometimes amplifying along the way. Approaches toward gender equity must anticipate both the discrete events and their predictable consequences. In some academic divisions, the impact of parental leave on scientific productivity has been moderated by providing additional support-not just during the leave, but for the surrounding period. Compensation plans can be modified so that increases in compensation tied to prior productivity are prorated for months on leave or at reduced activity. For example, if Dr. Okejumbe took parental leave in June and July, productivity measures that year could omit March through October. Such changes might also encourage more men to take parental leave-supporting gender equity along additional dimensions. Similar advantages are relevant to same gender partnerships. These approaches demonstrate an institutional commitment to supporting family life.

\section{CAREER TRACK}

Dr. Jones is completing an endocrinology fellowship at an elite academic institution. She loves patient care and her research in the molecular basis of multiple endocrine neoplasia syndromes. She meets with her division chief to discuss joining the faculty. She is told there is a physician-scientist track and a clinician-educator track and the physicianscientist track requires working extremely long hours.

Academic medicine offers diverse career opportunities. But even environments supporting immense career flexibility can inadvertently create gender inequities if women are structurally or implicitly discouraged from some options. For example, the American Board of Internal Medicine requires a training extension if leave exceeds 4 weeks. ${ }^{6}$ Some research funding mechanisms define eligibility based upon time since completing training or restrict grant extensions for childbearing. Beyond these structural impediments, perceptions about them or about the relative inflexibility of some career pathways may also affect men and women differently. These perceptions may lead more women into more clinical careers and, within those, into less procedurally-based fields. The 
challenge here is less that external markets support lower compensation in those fields - although they do-but more that women may be more likely to feel their choices are constrained. ${ }^{5}$

These considerations can be compounded by well-meaning chiefs and chairs but in fact is a form of what can be described as "benevolent" sexism which can be insidious. ${ }^{7}$ In remarking that the physician-scientist track requires working "extremely long hours," Dr. Jones's division chief might feel proud of being sensitive to work-life balance issues when talking to a young woman perhaps considering a family. However, the same issues might not be introduced with a man. Nor might the division chief, often selected because of scholarly accomplishments, recognize that success as a clinician-educator also takes long hours - or recognize that number of hours worked is often less important than control of those hours. Encouraging clinical roles is exactly right if that is what young physicians of any gender want, but inadvertently and preferentially nudging women in those directions may reduce start-up packages and future leadership opportunities.

Once recognized, these forces can be addressed. Building on the move to competency-based graduations, training organizations could reevaluate policies requiring training extensions for those taking parental leave. Institutions could move beyond measuring gender equity in tracks to requiring or incentivizing it. Early investigator awards could adjust timebased metrics to reflect life events, the way some academic promotion committees do, or move entirely past time-based metrics to those reflecting specific milestones regardless of timing. One promising example is the NIH program providing grant supplements supporting faculty reentering biomedical research after taking time off for family responsibilities.

\section{ACADEMIC PROMOTION}

Dr. Hernandez has made important contributions to understanding resistance to cancer immunotherapies. She has received considerable federal research funding and has published in leading journals. She is proposed for promotion to associate professor with tenure but is turned back at the school promotion committee because of concerns about her national and international reputation and her participation on institutional committees.

Academic promotion is considerably determined by external reputation. A component of reputation is evidenced by invited talks in distant locations and participation in national and international committees. Both activities require travelmore difficult for faculty with young children, particularly with both parents working outside the home. Many promotion committees also require evidence of institutional service. However, in academic medical centers with busy clinical services, committee meetings are often held before 8 or after 5 , times challenging times for parents with childcare responsibilities.

More sensitive support and accommodation is underway in some settings. Many conferences now arrange daytime childcare on site, although few extend to evenings when networking and other events have such added value. Some divisions and organizations offer grants to support bringing children and caregivers on work trips. More could be done enabling remote speaking and committee opportunities without requiring travel. Local committee participation is greatly facilitated when early morning and late evening meetings are seen as the exception not the norm, such as has happened at institutions like Johns Hopkins and the University of Pennsylvania.

\section{CONCLUSION}

Few if any leaders in medicine aim to perpetuate gender inequity. And yet a collection of forces - many wellmeaning - conspire to create relatively minor gender inequities that, over time, propagate and amplify. Eventually, they reveal themselves in the more marked differences in compensation, academic track, and promotion we continue to observe despite our best intentions. With experience, we learn how first-pass efforts at mitigating gender inequities typically do not go far enough. We should continue to test ourselves against the equity we achieve rather than the equity of our intentions and keep adjusting our processes until the two are aligned.

Corresponding Author: Aparna R. Parikh, Massachusetts General Hospital Cancer Center and Department of MedicineHarvard Medical School, Boston, MA, USA (e-mail: aparna.parikh@mgh.harvard.edu).

Author Contributions A.R.P., D.A.A., K.A., participated in writing and editing of the manuscript.

\section{Compliance with Ethical Standards:}

Conflict of Interest: A.R.P is a consultant/advisory board member for Puretech, Driver, Foundation Medicine and Eisai; and has institutional research funding from Array, Plexxikon, Guardant, BMS, MacroGenics, Genentech, Novartis, OncoMed, and Tolero.

D.A.A and K.A have no disclosures.

\section{REFERENCES}

1. Willett LL, Halvorsen AJ, McDonald FS, Chaudhry SI, Arora VM. Gender differences in salary of internal medicine residency directors: a national survey. Am J Med. 2015;128(6):659-665.

2. Freund KM, Raj A, Kaplan SE, et al. Inequities in Academic Compensation by Gender: A Follow-up to the National Faculty Survey Cohort Study. Academic medicine : journal of the Association of American Medical Colleges. 2016;91(8):1068-1073. 
3. Di Fiore F, Blanchard F, Charbonnier F, et al. Clinical relevance of KRAS mutation detection in metastatic colorectal cancer treated by Cetuximab plus chemotherapy. British journal of cancer. 2007;96(8): 1166-1169.

4. Jena AB, Olenski AR, Blumenthal DM. Sex Differences in Physician Salary in US Public Medical Schools. JAMA Intern Med. 2016;176(9):12941304.

5. Butkus R, Serchen J, Moyer DV, et al. Achieving Gender Equity in Physician Compensation and Career Advancement: A Position Paper of the American College of PhysiciansAchieving Gender Equity in Physician Compensation and Career Advancement. Annals of internal medicine. 2018;168(10):721-723.
6. https://www.abim.org/ /media/ABIM\%20Public/Files/pdf/publications/certification-guides/policies-and-procedures.pdf. Accessed Febuary 19, 2019. .

7. Dardenne, B., Dumont, M., \& Bollier, T. (2007). Insidious dangers of benevolent sexism: Consequences for women's performance. Journal of Personality and Social Psychology, 93(5), 764-779.

Publisher's Note Springer Nature remains neutral with regard to jurisdictional claims in published maps and institutional affiliations. 